\title{
Dose-related effects of formoterol on airway responsiveness to adenosine 5'-monophosphate and histamine
}

\author{
R.I. Ketchell, M.W. Jensen, D. Spina, B.J. O'Connor
}

\begin{abstract}
Dose-related effects of formoterol on airway responsiveness to adenosine 5'-monophosphate and histamine. R.I. Ketchell, M.W. Jensen, D. Spina, B.J. O'Connor. (C) ERS Journals Ltd 2002.

ABSTRACT: Inhaled short-acting $\beta_{2}$-agonists provide greater protection against airway responsiveness (AR) to the mast-cell stimulus, adenosine $5^{\prime}$-monophosphate (AMP), than to histamine, a direct spasmogen. Both terbutaline and albuterol exhibit this mast-cell stabilizing property in a dose-dependent manner. A single dose of the long-acting $\beta_{2}$-agonist formoterol has also been reported to have a mast cell-stabilizing effect, whereas salmeterol has not. To explore the dose-related actions of the longacting $\beta_{2}$-agonist formoterol on $A R$, the authors compared the acute effects of three doses of formoterol and terbutaline on AR to AMP and histamine.

In a double-blind, randomized, placebo-controlled, cross-over study, 25 mild, steroid naive, asthmatic subjects attended on 10 occasions. At each visit, subjects inhaled either a single dose of terbutaline $(500 \mu \mathrm{g})$, formoterol $(6,12$ or $24 \mu \mathrm{g})$ or a matched placebo, administered via Turbuhaler $\mathbb{R}, 30$ min prior to challenge with both AMP and histamine.

Each dose of $\beta_{2}$-agonist reduced AR to AMP and histamine. The bronchoprotective effects of formoterol $(6 \mu \mathrm{g})$ and terbutaline $(500 \mu \mathrm{g})$ were similar in magnitude in reducing AR to histamine (mean \pm SD: $3.6 \pm 0.3$ and $3.1 \pm 0.3$ doubling doses (DD)) and AR to AMP (3.5 \pm 0.5 and $3.3 \pm 0.4 \mathrm{DD}$, respectively). Overall, formoterol reduced $A R$ to both spasmogens in a dose-dependent manner. In addition, formoterol (12 and $24 \mu \mathrm{g}$ ) provided a significantly greater protective effect against AMP than against histamine challenge. It decreased AR by $5.7 \pm 0.6$ and $6.3 \pm 0.7 \mathrm{DD}$ against $\mathrm{AMP}$ and $4.3 \pm 0.4$ and 4.8 $\pm 0.43 \mathrm{DD}$ against histamine, respectively.

The results of this study indirectly demonstrated an in vivo dose-dependent mast-cell stabilizing effect of formoterol, in addition to functional antagonism on airway smooth muscle. This property of $\beta_{2}$-agonists may have clinical benefits in asthma management. Eur Respir J 2002; 19: 611-616.
\end{abstract}

Dept of Respiratory Medicine and Allergy, GKT School of Medicine, King's College, London, UK.

Correspondence: R.I. Ketchell Dept of Respiratory Medicine and Allergy

GKT School of Medicine

King's College

Bessemer Road

London

SE5 9PJ

UK

Fax: 442073463940

E-mail: ian.ketchell@kcl.ac.uk

Keywords: Adenosine

$5^{\prime}$-monophosphate

airway responsiveness

asthma

formoterol

Received: March 142001

Accepted after revision November 9 2001
The long-acting $\beta_{2}$-agonists formoterol and salmeterol are effective bronchodilators with a much longer duration of action than the short-acting $\beta_{2}$-agonists albuterol and terbutaline [1]. Their addition to low-dose inhaled glucocorticosteroids (GCS) is now recommended as an alternative to the use of high-dose inhaled corticosteroids in asthma management, especially in patients with nocturnal asthma or exerciseinduced symptoms [2]. In a similar manner to short-acting $\beta_{2}$-agonists, a single dose of formoterol may have a greater bronchoprotective effect on the indirect spasmogen, adenosine 5'-monophosphate (AMP), than on the direct-acting spasmogen, histamine [3-5]. In vitro and in vivo evidence of mast-cell mediator release and the attenuation of the bronchoconstrictive effects of AMP by the cromones and antihistamines suggest that AMP acts primarily as a mast-cell stimulus [6-8]. This implies an in vivo mastcell stabilizing effect of formoterol, in addition to functional antagonism on airway smooth muscle, an observation which, to date, has not been demonstrated with salmeterol $[9,10]$.
To further evaluate the in vivo mechanisms of formoterol, the effects of a single dose of formoterol (6, 12 and $24 \mu \mathrm{g}$ ), terbutaline $500 \mu \mathrm{g}$ (control) and a placebo on both AMP and histamine challenges were investigated. The authors aimed to prove that formoterol produced a dose-related reduction in airway responsiveness (AR). It was hypothesized that formoterol would provide greater, dose-dependent bronchoprotection against the mast-cell stimulus AMP, than against the direct histamine stimulus.

Methods

\section{Subjects}

Twenty-five nonsmoking subjects $(12$ males and 13 females) aged 23-42 yrs, took part in this study. All subjects had had mild asthma (forced expiratory volume in one second (FEV1) $>70 \%$ predicted), a positive skin-prick test to common airborne allergens (Dermatophagoides pteronyssinus, mixed grass pollen, 
or cat fur), a documented sensitivity to histamine (geometric provocative concentration causing a 20\% fall in FEV1 $\left(\mathrm{PC}_{20}\right)<2 \mathrm{mg} \cdot \mathrm{mL}^{-1}$ ) and AMP (geometric $\mathrm{PC}_{20}<25 \mathrm{mg} \cdot \mathrm{mL}^{-\mathrm{P}}$ ) during the previous 4 weeks. No subjects had an exacerbation of asthma or respiratory infection in the preceding 6 weeks. Each subject had infrequent symptoms, controlled with occasional inhaled short-acting $\beta_{2}$-agonists alone. No subject was taking any regular antiasthma therapy and none had taken inhaled corticosteroids for at least 3 months prior to entry. Written informed consent was obtained from each subject and the study was approved by the Ethics Committee of King's College Hospital.

\section{Study design}

It was a double-blind, placebo-controlled, crossover study and consisted of 10 treatment visits 3-7 days apart. Each subject received either terbutaline $(500 \mu \mathrm{g})$, formoterol $(6 \mu \mathrm{g})$, formoterol (one inhalation of $12 \mu \mathrm{g})$, formoterol $(24 \mu \mathrm{g}$, two inhalations of $12 \mu \mathrm{g}$ ) or a placebo at each visit, followed by either histamine or AMP challenge. Treatments were randomized using a Latin-square design. The order of the challenge was also randomized and subjects were blinded to the spasmogen delivered. Subjects received each treatment twice, once prior to histamine, the other before AMP challenge. Following baseline FEV1 (performed by an independent observer), subjects inhaled one actuation from each of three individual Turbuhalers $\AA$ (Astra Draco AB, Lund, Sweden). At each visit, subjects were instructed in the correct use of the Turbuhaler ( by an experienced Asthma Nurse Specialist to ensure they had the correct inhalation technique, flow rate and inspiratory hold time. Two inhalers were identical in appearance and contained $6-\mu \mathrm{g}$ formoterol, $12-\mu \mathrm{g}$ formoterol or matched placebo and the other contained $500-\mu \mathrm{g}$ terbutaline or a matched placebo. Thirty minutes later, spirometry was repeated by a second operator, blinded to initial FEV1, and subjects were then challenged with either histamine or AMP. Subjects refrained from using rescue medication and caffeinated beverages for $\geqslant 8 \mathrm{~h}$ prior to each visit and attended the laboratory at the same time each morning.

\section{Bronchial provocation and pulmonary function measurement}

Fresh solutions of histamine (Northwick Park and St Marks Hospitals, Harrow, UK) and AMP (Sigma, Poole, UK) were made up in $0.9 \%$ saline in concentrations from $0.0625-32 \mathrm{mg} \cdot \mathrm{mL}^{-1}$ for histamine and $0.39-800 \mathrm{mg} \cdot \mathrm{mL}^{-1}$ for AMP. Each solution was administered from a nebulizer attached to a breathactivated dosimeter (Mefar, Brescia, Italy). The nebulizer delivered particles with an aerodynamic mass median diameter of $3.5-4 \mu \mathrm{M}$ at a mean output of $9 \mu \mathrm{L} \cdot$ breath $^{-1}$.

Pulmonary function was assessed by measurement of FEV1 using a dry-wedge spirometer (Vitalograph,
Buckingham, UK). A standard challenge protocol was used for all provocation tests. Following a 15-min rest period, subjects performed three measurements of FEV1, 1 min apart, the best of which was taken as baseline. Subjects then inhaled five breaths of saline as a control, with an inhalation time of $1 \mathrm{~s}$ and breath-hold time of $6 \mathrm{~s}$. Providing FEV1 remained within $10 \%$ of the baseline, subjects continued by inhaling five breaths of doubling concentrations of spasmogen at 3-min intervals. FEV1 was measured at 1.5 - and 2.5 -min intervals following each challenge, and the highest value was recorded for analysis. Challenges were terminated when a $\geqslant 20 \%$ fall in FEV1 from postsaline was recorded or the maximum concentration had been given. A logarithmic concentration/response curve was constructed and the PC20 calculated by linear interpolation. If a $20 \%$ fall in FEV1 was not achieved after inhalation of the final concentration of spasmogen, the PC20 was estimated by applying the actual fall in FEV1 to the slope of the log concentration/response curve obtained at screening and a value obtained by linear extrapolation. The assumption that this dose/response curve did not change in the presence of $\beta_{2}$-agonist was made.

\section{Statistical methods}

Results are presented as mean \pm SEM, unless otherwise stated. Serial measurements within groups (baseline FEV1, change from baseline following treatment) were analysed by repeated-measures analysis of variance (ANOVA) and the difference between means was analysed using a paired t-test with Bonferroni's correction. PC20 values following inhalation of active and placebo treatments on each study day were logarithmically transformed for analysis, and the protective effect on each challenge was calculated using the formula:

$$
\frac{\text { Log } \mathrm{PC}_{20} \text { active }-\mathrm{PC}_{20} \text { placebo }}{\log 2}
$$

The results are expressed in terms of doubling dose (DD), mean \pm SEM.

The protective effects $\left(\log _{10}\right.$ active- $\log _{10}$ placebo) of the different $\beta_{2}$-agonist doses were analysed using two-way factorial analysis with repeated measures. Differences between means were analysed using an unpaired t-test with a Bonferroni's correction.

FEV1 values, following inhalation of the final four concentrations of spasmogen for each treatment (where a PC20 was achieved), were calculated as a percentage of the postsaline value (expressed as mean \pm SEM) and concentration/response curves were constructed and compared using one-way repeated ANOVA.

Using individual subject data, linear regression analysis of the $\log$ active- $\log$ placebo for each $\beta_{2}$-agonist dose was used to determine the dose-dependency of the bronchoprotective response. A p-value $<0.05$ was considered to be statistically significant. 
Table 1. - Airway calibre measured as forced expiratory volume in one second at baseline and 30 min after treatment prior to challenge with histamine and adenosine 5'-monophosphate (AMP)

\begin{tabular}{|c|c|c|c|c|c|c|}
\hline & \multicolumn{3}{|c|}{ Prehistamine challenge } & \multicolumn{3}{|c|}{ Pre-AMP challenge } \\
\hline & Before & After & $\%$ change & Before & After & $\%$ change \\
\hline Placebo & $3.53 \pm 0.13$ & $3.57 \pm 0.14$ & $1.1 \pm 1.0$ & $3.56 \pm 0.18$ & $3.58 \pm 0.13$ & $0.26 \pm 0.7$ \\
\hline Formoterol $6 \mu \mathrm{g}$ & $3.51 \pm 0.13$ & $3.82 \pm 0.15^{\#}$ & $9.0 \pm 1.2$ & $3.47 \pm 0.11$ & $3.74 \pm 0.13^{\#}$ & $7.61 \pm 1.5$ \\
\hline Formoterol $12 \mu \mathrm{g}$ & $3.53 \pm 0.13$ & $3.87 \pm 0.15^{\#}$ & $9.6 \pm 1.5$ & $3.52 \pm 0.13$ & $3.86 \pm 0.15^{\#}$ & $9.66 \pm 1.5$ \\
\hline Formoterol $24 \mu \mathrm{g}$ & $3.40 \pm 0.10$ & $3.81 \pm 0.13^{\#}$ & $12.1 \pm 1.8$ & $3.51 \pm 0.14$ & $3.84 \pm 0.15^{\#}$ & $9.71 \pm 1.5$ \\
\hline Terbutaline $500 \mu \mathrm{g}$ & $3.54 \pm 0.13$ & $3.86 \pm 0.16^{\#}$ & $8.9 \pm 1.5$ & $3.56 \pm 0.14$ & $3.88 \pm 0.15^{\#}$ & $9.34 \pm 1.6$ \\
\hline
\end{tabular}

Data are presented as mean \pm SEM, unless otherwise stated. ${ }^{*}: \mathrm{p}<0.0002$ versus placebo.

\section{Results}

After screening, all 25 randomized subjects (mean age $26.6 \pm 0.7 \mathrm{yrs}$ ), completed the study. The mean screening PC20 of spasmogen was $0.3 \pm 1.1 \mathrm{mg} \cdot \mathrm{mL}^{-1}$ and $3.55 \pm 1.2 \mathrm{mg} \cdot \mathrm{mL}^{-1}$ for histamine and AMP, respectively.

\section{Bronchodilation}

Mean baseline FEV1 was $91 \pm 2 \%$ pred, with no significant differences between visits. There was a significant increase in baseline FEV1 30-min postinhalation of a single dose of formoterol $(6,12$ and $24 \mu \mathrm{g})$ and terbutaline $(500 \mu \mathrm{g})$ relative to placebo $(\mathrm{p}<0.0002)$, prior to histamine and AMP challenges on each study day. Although there was a trend towards a dose-dependent increase in FEV1 following formoterol, this did not achieve significance (table 1).

\section{Bronchoprotection against histamine and adenosine 5'-monophosphate}

Following formoterol $(24 \mu \mathrm{g}), 11$ subjects failed to achieve PC20 after inhalation of the final concentration of AMP $\left(800 \mathrm{mg} \cdot \mathrm{mL}^{-1}\right)$. Following $12-\mu \mathrm{g}$ formoterol, nine subjects failed to achieve PC20, whereas one and two subjects failed to achieve PC20 after $6-\mu \mathrm{g}$ formoterol and 500- $\mu \mathrm{g}$ terbutaline, respectively. Following challenge with the highest concentration of histamine $\left(32 \mathrm{mg} \cdot \mathrm{mL}^{-1}\right)$, only one subject failed to achieve PC20 and this was after inhalation of $12-\mu \mathrm{g}$ formoterol.

The log PC20 for histamine and AMP challenge following placebo and $\beta_{2}$-agonist are presented in table 2. Formoterol induced dose-dependent bronchoprotection against both AMP $(\mathrm{p}=0.001)$ and histamine $(\mathrm{p}=0.033)$.

Analysis of the log active-log placebo data revealed that the $\beta_{2}$-agonist provided significant bronchoprotection against spasmogen $(\mathrm{F}(3,72)=34.9, \mathrm{p}<0.01)$. However, the bronchoprotection provided by the $\beta_{2}$-agonist was dependent upon the stimulus used, as reflected by a significant interaction $(F(3,72)=4.53$, $\mathrm{p} \leqslant 0.01)$. The bronchoprotective effect of $12-\mu \mathrm{g}$ formoterol was significantly greater against AMP $(5.7 \pm 0.6 \mathrm{DD})$ than against histamine $(4.3 \pm 0.4 \mathrm{DD})$ $(\mathrm{p}<0.01)$. Bronchoprotection following $24-\mu \mathrm{g}$ formoterol was also significantly greater against AMP $(6.3 \pm 0.7 \mathrm{DD})$ than against histamine $(4.8 \pm 0.43 \mathrm{DD})$ $(\mathrm{p}<0.01)$. In contrast, there was no significant difference between the bronchoprotective effect of inhaled formoterol at a dose of $6 \mu \mathrm{g}$ against AMP (3.5 \pm $0.5 \mathrm{DD})$ and histamine $(3.6 \pm 0.3 \mathrm{DD})$ or following inhaled terbutaline $500 \mu \mathrm{g}$ against AMP (3.3 \pm 0.4 DD) and histamine (3.1 \pm 0.3 DD) (fig. 1).

\section{Doselresponse curves}

The dose/response curves for AMP and histamine were similar in slope after inhalation of placebo and were not significantly altered by either terbutaline $(500 \mu \mathrm{g})$ or formoterol $(6,12$ or $24 \mu \mathrm{g})$ (fig. 2).

\section{Discussion}

The results of this study demonstrate the bronchodilator and bronchoprotective effects of acute

Table 2. - Bronchoprotective effect of formoterol and terbutaline on airway responsiveness to histamine and adenosine 5'-monophosphate (AMP)

\begin{tabular}{lccrr}
\hline & \multicolumn{2}{c}{ Histamine challenge } & \multicolumn{2}{c}{ AMP challenge } \\
\cline { 2 - 3 } & Log PC20 & PC20 $\left(\mathrm{mg} \cdot \mathrm{mL}^{-1}\right)$ & Log PC20 & PC20 $\left(\mathrm{mg} \cdot \mathrm{mL}^{-1}\right)$ \\
\hline Placebo & $-0.55 \pm 0.08$ & 0.28 & $0.77 \pm 0.11$ & 5.84 \\
Formoterol $6 \mu \mathrm{g}$ & $0.53 \pm 0.07$ & 3.38 & $1.81 \pm 0.13$ & 64.42 \\
Formoterol $12 \mu \mathrm{g}$ & $0.75 \pm 0.10$ & 5.58 & $2.49 \pm 0.19$ & 310.46 \\
Formoterol $24 \mu \mathrm{g}$ & $0.89 \pm 0.08$ & 7.8 & $2.67 \pm 0.18$ & 464.52 \\
Terbutaline $500 \mu \mathrm{g}$ & $0.38 \pm 0.08$ & 2.42 & $1.75 \pm 0.14$ & 56.36 \\
\hline
\end{tabular}

Data are presented as mean \pm SEM, unless otherwise stated. PC20: Provocation concentration of spasmogen causing a $20 \%$ fall in the forced expiratory volume in one second. 


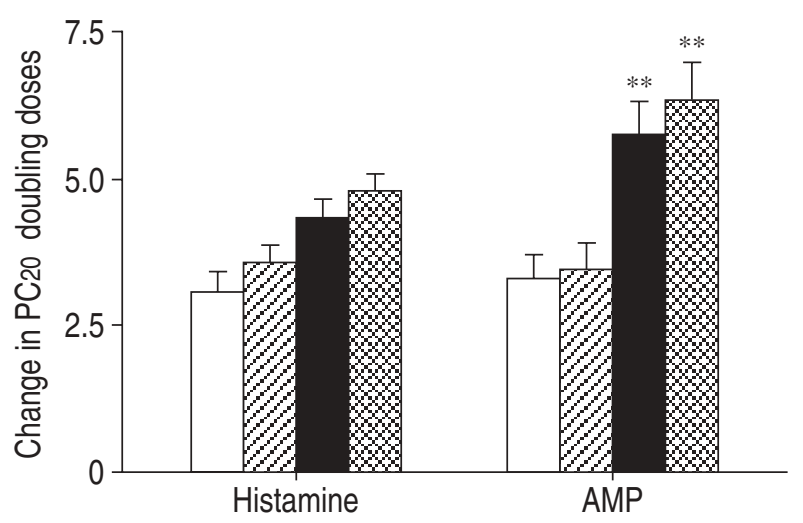

Fig. 1.-Doubling dose bronchoprotection of formoterol ( $\mathbb{Z}$ : $6 \mu \mathrm{g}$; 口: $12 \mu \mathrm{g}$; $\mathbf{2}: 24 \mu \mathrm{g}$ ) and terbutaline $(\square: 500 \mu \mathrm{g})$ relative to the placebo on airway responsiveness, $30 \mathrm{~min}$ before challenge with histamine and adenosine 5'-monophosphate (AMP). PC20: Provocative concentration of spasmogen causing a $20 \%$ fall in the forced expiratory volume in one second. Results are presented as means \pm SEM. **: $\mathrm{p}<0.01$, AMP versus histamine.

administration of both the short-acting $\beta_{2}$-agonist terbutaline and the long-acting $\beta_{2}$-agonist formoterol. A significant improvement in FEV1 30 min after each
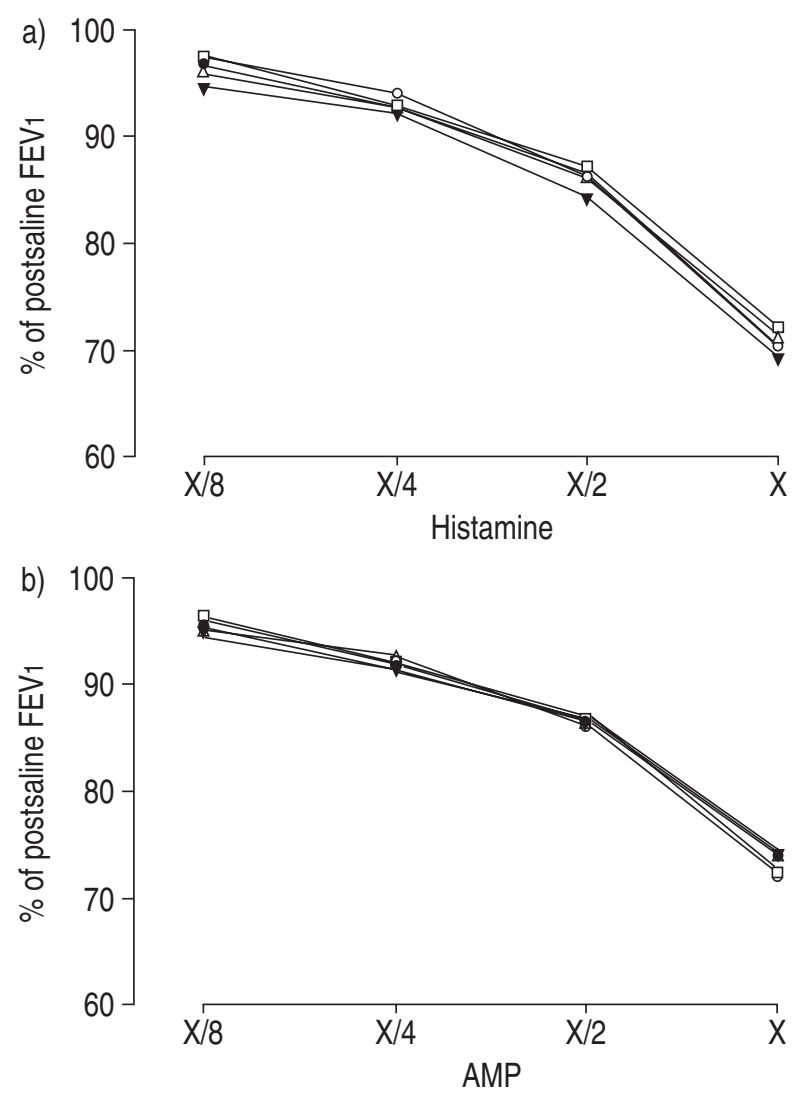

Fig. 2.-Dose/response curves for each spasmogen, a) histamine and b) adenosine $5^{\prime}$-monophosphate (AMP), following inhalation of placebo $(\square)$, formoterol $(\bullet: 6 \mu \mathrm{g} ; \triangle: 12 \mu \mathrm{g} ; \boldsymbol{\Lambda}: 24 \mu \mathrm{g})$ and terbutaline $(\bigcirc$ : $500 \mu \mathrm{g})$. Measured by forced expiratory volume in one second (FEV1) values (expressed as a percentage of the postsaline value), following the final four doubling doses of spasmogen in those subjects achieving a provocative concentration of spasmogen causing a $20 \%$ fall in FEV1. active treatment and a dose-dependent reduction in AR to both AMP and histamine following formoterol was observed. The two higher doses of formoterol produced a greater bronchoprotective effect against AMP compared to that against histamine, whereas $6-\mu \mathrm{g}$ formoterol and $500-\mu \mathrm{g}$ terbutaline reduced AR to both spasmogens to a similar extent.

The similarity between AMP and histamine dose/ response curves following placebo and each active treatment allows direct comparison of the bronchoprotection against each spasmogen. Thus, to explain the findings, it is likely that there are additional mechanisms to $\beta_{2}$-agonist-mediated functional antagonism against induced airway smooth muscle contraction. The greater degree of bronchoprotection against AMP afforded by formoterol compared with histamine, is consistent with previous studies on the differential effects of short-acting $\beta_{2}$-agonists on AR to these spasmogens [3]. This effect has been previously reported $30 \mathrm{~min}$ after a single dose of formoterol $(12 \mu \mathrm{g})$ [5] but not 2 or $14 \mathrm{~h}$ after a single dose of salmeterol $(50 \mu \mathrm{g})[9,10]$.

Both short- and long-acting $\beta_{2}$-agonists inhibit mast mediator release in vitro [11-13]. As the major bronchoconstrictive effect of AMP results from mast-cell degranulation and mediator release [6-8], the additional bronchoprotection seen with the higher doses of formoterol is likely to be due to its mast-cell stabilizing properties. The difference between the in vivo effect of formoterol and salmeterol is surprising as they have similar effects on mast cells in vitro [11-13]. The differences in the pharmacological properties of salmeterol and formoterol may provide an explanation for the lack of an additional effect of a single dose of salmeterol $(50 \mu \mathrm{g})$, against AMP in previous studies $[9,10]$. Salmeterol, a partial agonist, may simply not achieve adequate levels of receptor occupancy on mast cells at this dose. Indeed, salmeterol is two-fold less potent than formoterol in relaxing human smooth muscle in vitro and is $\geqslant 20$-fold less active than formoterol at inhibiting mast-cell degranulation [11].

An alternative explanation for the additional bronchoprotective effect of formoterol must be considered. In addition to its effect on mast-cell degranulation and mediator release, adenosine, the active metabolite of AMP, may have direct effects on mucosal blood flow, microvascular leakage and contractile neuropeptide release from sensory nerve endings via A2b receptors [14-16]. Since formoterol inhibits plasma exudation on postcapillary venule cells and neuropeptide release from sensory nerves [17] via $\beta_{2}$-receptors, it is plausible that some of its nonsmooth muscle effects involve pathways that are independent of its mast-cell stabilizing properties.

As the authors had shown an additional bronchoprotective effect of $500-\mu \mathrm{g}$ terbutaline against AMP in two previous studies [3, 18], they were surprised that there was no significant difference between the bronchoprotective effect of the same doses of terbutaline against histamine and AMP in the present study. The possibility that the bronchoprotective effect of terbutaline had worn off at the time of completion of AMP challenge was considered. The maximum 
possible time between inhalation of treatment and the completion of each challenge was $63 \mathrm{~min}$ for histamine and $69 \mathrm{~min}$ for AMP (30 min before the start of challenge and $\leqslant 39 \mathrm{~min}$ to administer all doses of spasmogen). Mean times (95\% confidence intervals) for completion of histamine and AMP challenges were $53.6 \mathrm{~min}(50.3-54.9)$ and $58.9 \mathrm{~min}$ (56.1-61.7), respectively. Short-acting $\beta_{2}$-agonists protected against histamine for $\leqslant 4 \mathrm{~h}$ with a peak of between $1-2 \mathrm{~h}[19,20]$ and $500-\mu \mathrm{g}$ terbutaline protected against exercise-induced asthma for $\leqslant 2 \mathrm{~h}$ [21]. It is unlikely, therefore, that the timing of the challenges could explain the results.

The 3.1 DD bronchoprotection against histamine was greater than the 2.1 and 2.7 previously reported by the authors and the DD protection following the same dose of terbutaline against methacholine $[3,18]$. The geometric mean PC20 to histamine of $0.28 \mathrm{mg} \cdot \mathrm{mL}^{-1}$ after placebo was much lower than in a previous study by the authors, in which the values after placebo were 1.04 and $0.91 \mathrm{mg} \cdot \mathrm{mL}^{-1}$. It is possible that the acute effect of terbutaline on histamine is greater in subjects with more severe AR. There was no other difference in subject characteristics and the same inhaler device was used in each of the studies.

Higher doses of the short-acting partial agonist albuterol (400 $\mu \mathrm{g}$ via Diskhaler) [9] and albuterol (2.5 mg nebulized) [4] provided greater bronchoprotection to AMP than histamine, a finding not seen at the lower dose of albuterol, $200 \mu \mathrm{g}$ via Turbuhaler ( [5]. The authors have also previously demonstrated dose-dependent additional bronchoprotection of terbutaline against AMP relative to methacholine [3]. Therefore, the lack of additional bronchoprotection following 6- $\mu \mathrm{g}$ formoterol or $500-\mu \mathrm{g}$ terbutaline in this study provides further evidence that the presumed mast-cell stabilizing effects of $\beta_{2}$-agonists are dose-dependent.

The failure of a number of subjects to achieve a PC20 to AMP following treatment with formoterol may have led to an underestimation of the bronchoprotective effect against AMP. The highest dose of AMP available for inhalation was $800 \mathrm{mg} \cdot \mathrm{mL}^{-1}$, and a PC20 was not achieved in 11 of the 25 subjects after $24-\mu \mathrm{g}$ formoterol, in nine subjects after $12-\mu \mathrm{g}$ formoterol and in one subject after $6-\mu \mathrm{g}$ formoterol. To overcome this and to obtain an estimate of the true PC20 for these subjects, the slope of the screening AMP concentration/ response curve was utilized. By fitting the maximum per cent FEV1 fall achieved following $800 \mathrm{mg} \cdot \mathrm{mL}^{-1}$ of AMP to that slope, the $\log$ PC20 by linear extrapolation was determined. This assumed that $\beta_{2}$-agonist treatment did not alter the slope of the AMP dose/response curve. The parallel shift in dose/response curves after each treatment in subjects achieving a PC20 suggested that the authors' assumption was correct (fig. 2). Therefore, the failure of a number of subjects to achieve $\mathrm{PC}_{20}$ at the highest concentration of AMP was unlikely to have significantly influenced the true bronchoprotective effect of formoterol (12 and $24 \mu \mathrm{g})$.

The clinical relevance of the additional bronchoprotective effect of a single dose of formoterol against AMP compared to histamine remains uncertain.
Long-acting $\beta_{2}$-agonists are not used as monotherapy but only in conjunction with inhaled GCS [2]. Therefore, any mast-cell effects of long-acting $\beta_{2}$-agonists would be in addition to the known ability of inhaled corticosteroids to deplete airway mast-cell numbers $[22,23]$. However, inhaled corticosteroids do not fully protect against allergen- or exercise-induced bronchospasm, which are both regarded as mast-cell mediated events $[23,24]$. This suggests that even in the presence of inhaled corticosteroids there are potentially active mast cells residing in the airways and it is possible that $\beta_{2}$-agonists would confer additional benefit. The addition of formoterol to inhaled budesonide improves symptoms and lung function and reduces asthma exacerbations over a 12-month period [25]. Furthermore, recent evidence from TATTERSFIELD et al. [26] suggested that as-needed treatment with formoterol provided better asthma control than terbutaline in patients requiring moderate doses of relief medication, despite inhaled GCS treatment. Although this additional benefit of formoterol requires further explanation, it is probably due to a nonbronchodilator action that may involve modulation of the inflammatory process.

This study clearly shows a nonsmooth muscle action of formoterol, which the authors believe is due to an effect on the mast cells. This dose-dependent mast-cell stabilizing effect occurs 30-min after a single dose of formoterol. The rapid onset of both the bronchodilator and bronchoprotective effects of therapeutic doses of formoterol may have a beneficial effect against mast-cell stimuli, such as inhalation of allergen and exercise, in addition to functional antagonism on bronchial smooth muscle. These benefits may account for the improvement seen in asthma control with the combination of long-acting $\beta_{2}$-agonist and inhaled glucocorticosteroids. Further study of the mechanisms governing the action of formoterol and related molecules is required.

\section{References}

1. Palmqvist M, Persson G, Lazer L, Rosenborg J, Larsson P, Lotvall J. Inhaled dry-powder formoterol and salmeterol in asthmatic patients: onset of action, duration of effect and potency. Eur Respir J 1997; 10: 2484-2489.

2. British Thoracic Society. The British guidelines on asthma management 1995 review and position statement - Introduction. Thorax 1997; 52: S1-S21.

3. O'Connor BJ, Fuller RW, Barnes PJ. Nonbronchodilator effects of inhaled beta2 agonists: Greater protection against adenosine monophosphate- than methacholine-induced bronchoconstriction in asthma. Am J Respir Crit Care Med 1994; 150: 381-387.

4. Phillips GD, Finnerty JP, Holgate ST. Comparative protective effect of the inhaled beta2-agonist salbutamol (albuterol) on bronchoconstriction provoked by histamine, methacholine, and adenosine $5^{\prime}$-monophosphate in asthma. J Allergy Clin Immunol 1990; 85: 755-762.

5. Nightingale JA, Rogers DF, Barnes PJ. Differential effect of formoterol on adenosine monophosphate 
and histamine reactivity in asthma. Am J Respir Crit Care Med 1999; 159: 1786-1790.

6. Forsythe P, McGarvey LPA, Heaney LG, Macmahon $\mathrm{J}$, Ennis M. Adenosine induces histamine release from human bronchoalveolar lavage mast cells. Clin Science 1999; 96: 349-355.

7. Polosa $\mathrm{R}, \mathrm{Ng} \mathrm{WH}$, Crimi $\mathrm{N}$, et al. Release of mastcell-derived mediators after endobronchial adenosine challenge in asthma. Am J Respir Crit Care Med 1995; 51: 624-629.

8. Polosa R, Holgate ST. Adenosine bronchoprovocation: a promising marker of allergic inflammation in asthma? Thorax 1997; 52: 919-923.

9. Taylor DA, Jensen MW, Aikman SL, Harris JG, Barnes PJ, O'Connor BJ. Comparison of salmeterol and albuterol-induced bronchoprotection against adenosine monophosphate and histamine in mild asthma. Am J Respir Crit Care Med 1997; 156: 1731-1737.

10. Soler M, Joos L, Bolliger CT, Elsasser S, Perruchoud AP. Bronchoprotection by salmeterol-cell stabilization or functional antagonism-comparative effects on histamine-induced and AMP-induced bronchoconstriction. Eur Respir J 1994; 7: 1973-1977.

11. Nials AT, Ball DI, Butchers PR, et al. Formoterol on airway smooth muscle and human lung mast-cells - a comparison with salbutamol and salmeterol. Eur J Pharmacol 1994; 251: 127-135.

12. Butchers PR, Vardey CJ, Johnson M. Salmeterol - a potent and long-acting inhibitor of inflammatory mediator release from human lung. Brit $J$ Pharmacol 1991; 104: 672-676.

13. Chong LK, Cooper E, Vardey CJ, Peachell PT. Salmeterol inhibition of mediator release from human lung mast cells by beta-adrenoceptor-dependent and independent mechanisms. Br J Pharmacol 1998; 123: 1009-1015.

14. Haynes J, Obiako B, Thompson WJ, Downey J. Adenosine-induced vasodilation: receptor characterization in pulmonary circulation. Am J Physiol 1995; 268: H1862-H1868.

15. Gawlowski DM, Duran WN. Dose-related effects of adenosine and bradykinin on microvascular permselectivity to macromolecules in the hamster-cheek pouch. Circ Res 1986; 58: 348-355.
16. Feoktistov I, Biaggioni I. Adenosine A(2B) receptors. Pharmacol Rev 1997; 49: 381-402.

17. Barnes PJ. Effect of beta-agonists on inflammatory cells. J Allergy Clin Immunol 1999; 104: S10-S17.

18. $\mathrm{O}^{\prime}$ Connor BJ, Aikman SL, Barnes PJ. Tolerance to the nonbronchodilator effects of inhaled beta-2-agonists in asthma. N Eng J Med 1992; 327: 1204-1208.

19. Gongora HC, Wisniewski AFZ, Tattersfield AE. A single-dose comparison of inhaled albuterol and two formulations of salmeterol on airway reactivity in asthmatic subjects. Am Rev Respir Dis 1991; 144: 626629.

20. Ahrens RC, Harris JB, Milavetz G. Use of bronchial provocation with histamine to compare the pharmacodynamics of inhaled albuterol and metaproterenol in patients with asthma. J Allergy Clin Immunol 1987; 79: 876-882.

21. Woolley M, Anderson SD, Quigley BM. Duration of protective effect of terbutaline sulfate and cromolyn sodium alone and in combination on exercise-induced asthma. Chest 1990; 97: 39-45.

22. Laitinen LA, Laitinen A, Haahtela T. A comparativestudy of the effects of an inhaled corticosteroid, budesonide, and a beta-2-agonist, terbutaline, on airway inflammation in newly diagnosed asthma - a randomized, double-blind, parallel-group controlled trial. J Allergy Clin Immunol 1992; 90: 32-42.

23. Barnes PJ. Effect of corticosteroids on airway hyperresponsiveness. Am Rev Respir Dis 1990; 141: S70-S76.

24. Gauvreau GM, Doctor J, Watson RM, Jordana M, Obyrne PM. Effects of inhaled budesonide on allergeninduced airway responses and airway inflammation. Am J Respir Crit Care Med 1996; 154: 12671271.

25. Pauwels RA, Löfdahl CG, Postma DS, et al. Effect of inhaled formoterol and budesonide on exacerbations of asthma. Formoterol and Corticosteroids Establishing Therapy (FACET) International Study Group. $N$ Eng J Med 1997; 337: 1405-1411.

26. Tattersfield AE, Löfdahl CG, Postma DS, et al. Comparison of formoterol and terbutaline for asneeded treatment of asthma: a randomised trial. Lancet 2001; 357: 257-261. 